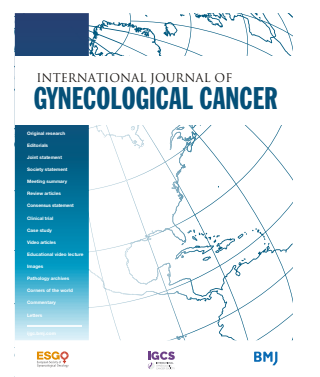

\title{
Ultrasound, macroscopic and histological features of malignant ovarian tumors. Non-epithelial ovarian carcinomas: tubal choriocarcinoma and granulosa cell tumor
}

Lorena Quagliozzi, ${ }^{1}$ Viviana Lo Presti, ${ }^{1}$ Damiano Arciuolo, ${ }^{2}$ Floriana Mascilini (D) 1

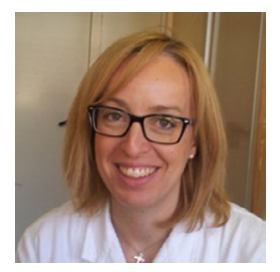

\section{Floriana Mascilini}

${ }^{1}$ Dipartimento Scienze della Salute della Donna, del Bambino e di Sanità Pubblica, Fondazione Policlinico Universitario A Gemelli, IRCCS, Rome, Italy

Biography: Dott.ssa Floriana Mascilini is a gynecologist of Fondazione Policlinico Universitario Agostino Gemelli, IRCCS, in Rome. She is particularly involved in clinical research in ultrasound and gynecologic oncology.

For numbered affiliations see end of article.

\section{Correspondence to} Dr Floriana Mascilini, Dipartimento Scienze della Salute della Donna, del Bambino e di Sanità Pubblica, Fondazione Policlinico Universitario A. Gemelli, IRCCS, 00168 Rome, Italy; floriana mascilini@hotmail.com

Accepted 8 October 2020 Published Online First 2 November 2020
The first case is a 31-year-old woman with no family history of cancer, and a past medical history of miscarriage diagnosed 7 months before. The patient was referred to our center for a right adnexal mass incidentally detected during an ultrasound examination performed at another hospital for irregular bleeding. Serum levels of oncological markers were: CA 125: $10.0 \mathrm{U} / \mathrm{mL}$ (reference range $0-35 \mathrm{U} / \mathrm{mL}$ ), human epididymis protein 4: $46.1 \mathrm{pmol} / \mathrm{L}$ (reference range $0-150 \mathrm{pmol} / \mathrm{L}$ ), and serum levels of $\beta$-human chorionic gonadotropin: $14240 \mathrm{mU} / \mathrm{mL}$. Transvaginal ultrasound examination performed at our center showed an oblong solid mass of $85 \times 34 \times 75 \mathrm{~mm}$ in size, situated medially to the right ovarian parenchyma, with inhomogeneous echostructure, irregular external walls, and no stripes (Figure 1A). ${ }^{1}$ Uterus, left and right ovaries were normal. At color Doppler examination, a moderate vascularization was detected within the adnexal lesion.

We applied the IOTA ADNEX model, ${ }^{2}$ which showed an increased risk of malignancy, with highest relative risk for stage I ovarian cancer (link to the IOTA ADNEX model calculator: https://www.iotagroup.org/ sites/default/files/adnexmodel/IOTA-ADNEXmodel. $\mathrm{html}$ ). Moreover, the tumor was classified as 0-RADS 4 (Ovarian-Adnexal Reporting and Data System). ${ }^{3}$
Check for updates

C IGCS and ESGO 2021. No commercial re-use. See rights and permissions. Published by BMJ.

\footnotetext{
To cite: Quagliozzi L, Lo Presti V, Arciuolo D, et al. Int J Gynecol Cancer 2021;31:1090-1091.
}
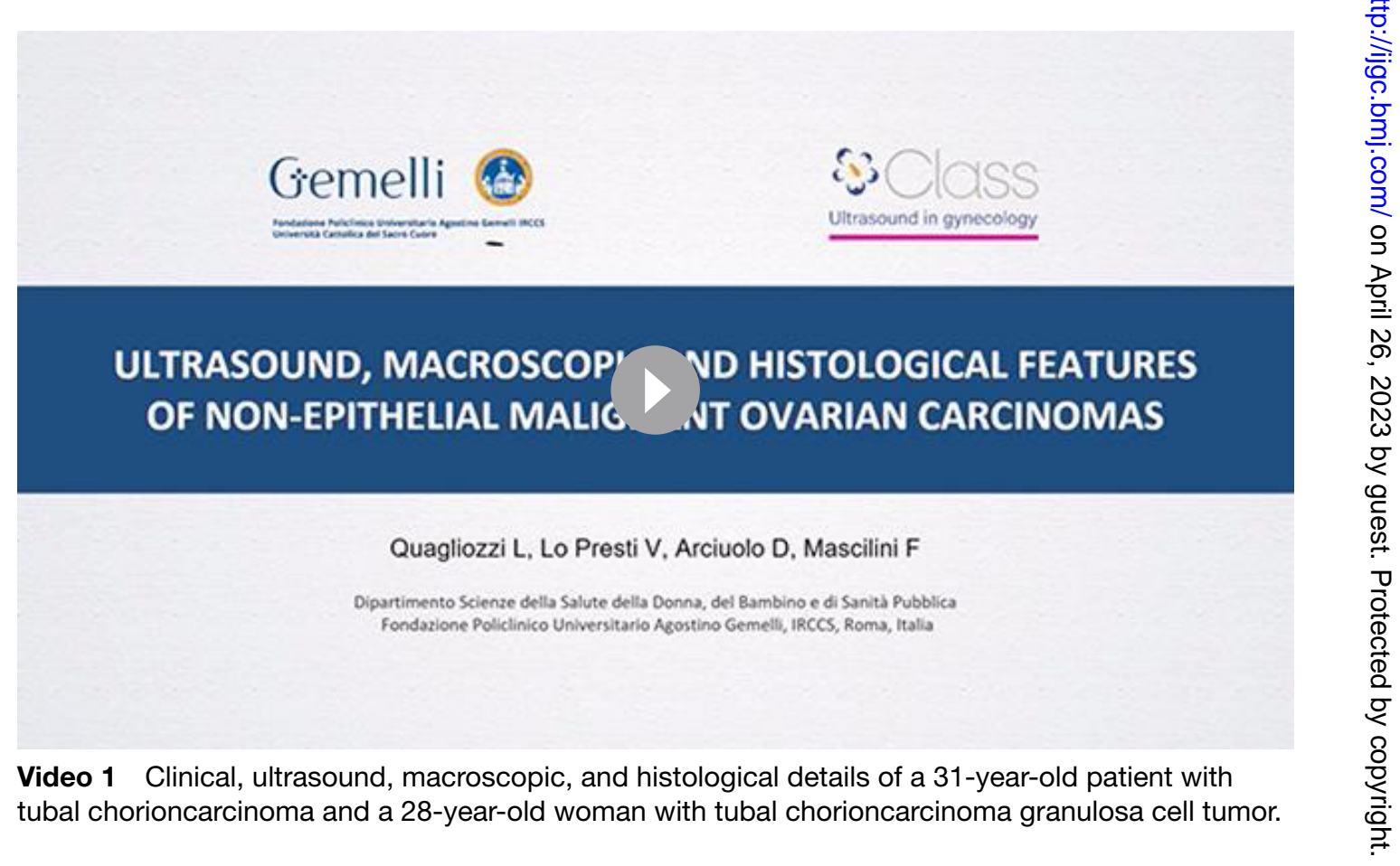

\section{ULTRASOUND, MACROSCOP VD HISTOLOGICAL FEATURES OF NON-EPITHELIAL MALIG NT OVARIAN CARCINOMAS}




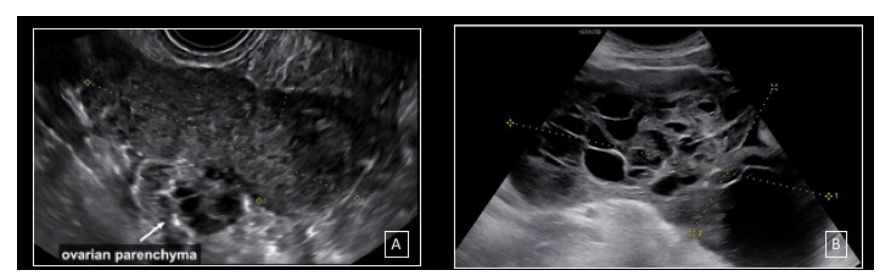

Figure 1 (A) An oblong solid mass, with inhomogeneous echostructure and irregular external walls, without stripes. (B) Multilocular solid mass, with several irregular locules, anechoic cystic content, and a solid component.

At laparoscopy the surgeon confirmed the presence of a solid tumor of tubal origin with normal ovarian parenchyma in the right adnexal region, and a biopsy of the solid mass was performed. The patient, informed of the potential risk of spreading the tumor by having a biopsy, wished to postpone any radical surgery after the acquisition of the definitive histological examination. At final histology, fragments of tubular tissue in the aggregate seat of solid neoplasia consisting of cytotrophoblastic and syncytiotrophoblastic elements with marked atypia, in the absence of villar structures, were observed. ${ }^{4}$ Immune histochemical staining ultimately confirmed the diagnosis of tubal choriocarcinoma.

A chest CT scan documented pulmonary metastases (FIGO stage IV). The patient was treated with chemotherapy, including six cycles of EMACO (etoposide, methotrexate, actinomycin D, cyclophosphamide, vincristine/oncovine). Serum levels of $\beta$-human chorionic gonadotropin decreased from 14240 to $6000 \mathrm{mlU} / \mathrm{mL}$ after one cycle of chemotherapy and they were within the normal range after six cycles. At ultrasound examination performed 1 month after the last cycle of chemotherapy, the right solid adnexal lesion appeared smaller than in the first scan $(65 \times 23 \times 39 \mathrm{~mm}$ in size $)$, and it showed minimal vascularization. A surgical procedure, including hysterectomy, left salpingectomy, and right salpingo-0ophorectomy, was performed. Macroscopy showed the presence of a dilated fallopian tube with yellowish necrotic debris. At microscopy, necrotic and hemorrhagic areas with giant-cell granulomatous reaction, without evidence of residual neoplastic cells, were reported.

The second case is a 28-year old woman with family history of colon cancer (maternal grandmother). The patient was referred to our center for a pelvic mass detected during a transvaginal ultrasound examination performed at another hospital for abdominal distension. Serum levels of oncological marker CA 125 was $757 \mathrm{U} /$ $\mathrm{mL}$ (reference range $0-35 \mathrm{U} / \mathrm{mL}$ ).

Transvaginal ultrasound examination performed at our center showed a normal uterus and left ovary and a voluminous mass on the right side with rich vascularization at color Doppler examination. Solid tissue with irregular margins and inhomogeneous echostructure was also seen in the pouch of Douglas. The transabdominal ultrasound examination confirmed the presence of a right multilocular solid mass of $184 \times 94 \times 130 \mathrm{~mm}$ in size, with several irregular locules, anechoic cystic content, and a solid component of $56 \times 33 \mathrm{~mm}$ in size (Figure 1B). ${ }^{5}$ Ascites, right diaphragmatic carcinomatosis, and lesser omentum carcinomatosis were also described. Using pattern recognition, the ultrasound examiner suspected a mucinous malignant ovarian tumor. IOTAADNEX model ${ }^{2}$ showed an increased risk of malignancy, with highest relative risk for borderline ovarian tumor and for stage II-IV ovarian cancer (link to the IOTA ADNEX model calculator: https://www.iotagroup.org/ sites/default/files/adnexmodel/IOTA-ADNEXmodel.html). Moreover, the tumor was classified as 0-RADS $5 .^{3}$

Laparoscopy confirmed the presence of a voluminous pelvic mass. Therefore, the patient underwent laparotomy and a right salpingoophorectomy was performed. During laparotomy, white plaques in the pouch of Douglas were observed. Peritoneal and omental biopsies were performed. The macroscopic assessment of the mass confirmed the presence of a multilocular solid tumor. Final histology report was positive for granulosa cell tumor, adulttype. ${ }^{67}$ Peritoneal and omental biopsies were negative for atypical cells (FIGO stage 1C2).

\section{Author affiliations}

${ }^{1}$ Dipartimento Scienze della Salute della Donna, del Bambino e di Sanità Pubblica, Fondazione Policlinico Universitario A Gemelli, IRCCS, Rome, Italy

${ }^{2}$ Department of Surgical Pathology, Policlinico A Gemelli, Rome, Italy

Acknowledgements We thank Professor Antonia Carla Testa, Professor Giovanni Scambia, and Dr Francesca Moro, Dipartimento Scienze della Salute della Donna, del Bambino e di Sanità Pubblica, Fondazione Policlinico Universitario Agostino Gemelli, IRCCS, Roma, Italia for the scientific supervision. We also thank Dr Paola Romeo, Dr Valeria Verdecchia, and Mr Emerson Marinho Pinto, Dipartimento Scienze della Salute della Donna, del Bambino e di Sanità Pubblica, Fondazione Policlinico Universitario Agostino Gemelli, IRCCS, Roma, Italia for the realization of the video.

Contributors FM, LQ did the study design, patient recruitment, and wrote the report. VLP participated in patient recruitment. DA performed the histological examination. All authors approved the final report.

Funding The authors have not declared a specific grant for this research from any funding agency in the public, commercial or not-for-profit sectors.

Competing interests None declared.

Patient consent for publication Not required.

Provenance and peer review Not commissioned; externally peer reviewed.

\section{ORCID iD}

Floriana Mascilini http://orcid.org/0000-0003-0736-3114

\section{REFERENCES}

1 Ludovisi M, De Blasis I, Virgilio B, et al. Imaging in gynecological disease (9): clinical and ultrasound characteristics of tubal cancer. Ultrasound Obstet Gynecol 2014;43:328-35.

2 Van Calster B, Van Hoorde K, Valentin L, et al. Evaluating the risk of ovarian cancer before surgery using the ADNEX model to differentiate between benign, borderline, early and advanced stage invasive, and secondary metastatic tumours: prospective multicentre diagnostic study. BMJ 2014;349:g5920.

3 Andreotti RF, Timmerman D, Strachowski LM, et al. O-RADS US risk stratification and management system: a consensus guideline from the ACR ovarian-adnexal reporting and data system committee. Radiology 2020;294:168-85.

4 Vang R, Wheeler JE. Diseases of the fallopian tube and paratubal region. In: Kurman RJ, Ellenson LH, Ronnett BM, eds. Blaustein's Pathology of the Female Genital Tract. 6th edn. New York: SpringerVerlag, 2011: 554-69.

5 Van Holsbeke C, Domali E, Holland TK, et al. Imaging of gynecological disease (3): clinical and ultrasound characteristics of granulosa cell tumors of the ovary. Ultrasound Obstet Gynecol 2008;31:450-6.

6 Fox H, Agrawal K, Langley FA. A clinicopathologic study of 92 cases of granulosa cell tumor of the ovary with special reference to the factors influencing prognosis. Cancer 1975;35:231-41.

7 Young RH, Scully RESex cord-stromal steroid cell and other ovarian tumors with endocrine, paraendocrine, and paraneoplastic manifestations. In: Kurman RJ, ed. Blaustein's Pathology of the Female Genital Tract. 4th edn. New York, NY: Springer- Verlag, 1994: 783-97. 